\title{
Studies on photostability of butyrylated, milled wood lignin using spectroscopic analyses
}

\author{
Hui-Ting Chang ${ }^{\text {a }}$, Yu-Chang Su ${ }^{\text {b }}$, Shang-Tzen Chang ${ }^{a, *}$ \\ ${ }^{a}$ School of Forestry and Resource Conservation, National Taiwan University, No. 1, Sec. 4, Roosevelt Road, 106 Taipei, Taiwan \\ ${ }^{\mathrm{b}}$ Division of Wood Cellulose, Taiwan Forestry Research Institute, Council of Agriculture, Executive Yuan, 106 Taipei, Taiwan
}

Received 5 May 2005; accepted 27 June 2005

Available online 11 August 2005

\begin{abstract}
Photo-stabilisation of butyrylated milled wood lignin (MWL) was investigated in this study. Chemical changes were confirmed by NMR and FT-IR spectra after butyrylation. Improvements in the photostability of MWL by butyrylation were evaluated by spectral analyses including ESR, FT-IR and UV-VIS spectra. From ESR analyses, butyrylation reduces the amount of phenoxyl free radicals of MWL after UV irradiation, which results in inhibiting the photo-oxidation of lignin followed by a significant decrease in the formation of colored chromophores. The carbonyl, carboxyl and quinonoid structures were less detected in the butyrylated MWL after UV irradiation than those of untreated MWL, and the content of degraded water-soluble materials from the photo-degradation of MWL was also reduced upon butyrylation.
\end{abstract}

(C) 2005 Elsevier Ltd. All rights reserved.

Keywords: Milled wood lignin; Phenoxyl radical; Photodegradation; Chemical modification; Butyrylation; NMR; FT-IR; ESR; Light stability

\section{Introduction}

Lignin is not only one of the major components of lignocellulosic materials but also an abundant natural polymeric material on earth [1]. Lignin is an amorphous, polyphenolic material arising from an enzyme-mediated dehydrogenative polymerization of three phenylpropanoid monomers, coniferyl, sinapyl and $p$-coumaryl alcohols. The functional groups attached to the phenylpropanoid skeleton include phenolic hydroxyl, benzylic hydroxyl, and carbonyl groups. As a consequence of light absorption by lignin chromophores, lignin is destroyed by UV light. Initially, the discoloration of lignocellulosic material is readily observed [2-5]. It is found that the main chemical species causing the photo-discoloration of wood or high-yield pulps is lignin [6-11].

\footnotetext{
* Corresponding author. Tel.: +886233665880; fax: +886223654520.

E-mail address: peter@ntu.edu.tw (S.-T. Chang).
}

Four possible routes have been proposed for the photo-oxidation of lignin. Route 1: direct absorption of UV light by conjugated phenolic groups to form the phenoxyl radicals; route 2: abstraction of phenolic hydroxyl hydrogen as a result of aromatic carbonyl triplet excitation to produce ketyl and phenoxyl radicals; route 3: cleavage of non-phenolic phenacyl- $\alpha-O$ arylethers to phenacyl-phenoxyl radical pairs; and route 4: abstraction of the benzylic hydrogen of the guaiacylglycerol- $\beta$-arylether group to form the phenoxyl radicals [7]. The phenoxyl radicals would readily be oxidized to form the quinonoid colored chromophores [6,7]. Resolving the problem of photo-discoloration of wood or lignin-rich pulps remains a challenging area of wood chemistry and pulp and papermaking research.

There are two modes of inhibiting photo-yellowing of lignin-containing materials. The first mode involves the use of chemical additives applied to the wood or high lignin-containing paper to block UV light using UV absorbing compounds or quenching the phenoxy 
free-radical with hydrogen donating compounds [7,1113]. The second mode involves chemical modification of lignin by substitution of the phenolic hydroxyl group so as to stop the initiation and subsequent radical reactions of reactive functional groups leading to the formation of chromophoric derivatives [14-16]. Paulsson et al. reported that the chromophores formed during UV irradiation of acetylated chemithermomechanical pulp (CTMP) were substantially less in the whole UV-VIS region [17]. In our previous study, the efficiency of butyrylation in preventing the photo-discoloration of wood was more remarkable than that of acetylation $[18,19]$. The detailed mechanisms of photo-yellowing inhibition of butyrylated wood need further investigations.

The MWL has been used as a representative source of native lignin. Therefore, the photochemistry of lignin has been frequently studied with MWL $[6,11,20]$. In this paper we report the chemical changes of MWL during photo-oxidation by FT-IR and ESR spectroscopies, the chemical characteristics of MWL after butyrylation, and the photo-stabilising effect on milled wood lignin of butyrylation.

\section{Material and methods}

\subsection{Preparation of milled wood lignin}

China fir (Cunninghamia lanceolata var. lanceolata) sawdust (60 mesh) was extracted in a Soxhlet apparatus with alcohol-toluene $(1: 2, \mathrm{v} / \mathrm{v})$ for $24 \mathrm{~h}$, followed by another extraction with water for $24 \mathrm{~h}$ and then ovendried at $105^{\circ} \mathrm{C}$. The milled wood lignin (MWL) was isolated using a planetary ball mill (Retsch PM400) according to methods reported elsewhere [21,22].

\subsection{Butyrylation of milled wood lignin}

Milled wood lignin was immersed in neat liquid butyric anhydride and heated at $125{ }^{\circ} \mathrm{C}$ for $3 \mathrm{~h}$. After the treatment, the butyrylated MWL specimens were purified to remove unreacted anhydride, and then ovendried. The weight gain $\left(W_{\mathrm{G}}\right)$ of MWL after butyrylation was $36 \%$.

\section{3. ${ }^{1} H$ NMR spectra}

${ }^{1} \mathrm{H}$ NMR $\left({ }^{1} \mathrm{H}\right.$ nuclei magnetic resonance) spectra were obtained by the Bruker DMX-300 FT-NMR spectrometer using DMSO $-d_{6}$ as the solvent. Chemical shifts were calculated relative to TMS (tetramethylsilane) for spectrometer control.

\subsection{FT-IR spectra}

The FT-IR spectra were obtained using a Bio-Rad FTS-40 spectrometer incorporating a Spectra Tech diffuse reflectance accessory unit. The spectral resolution was $4 \mathrm{~cm}^{-1}$ and the scanning range was from 400 to $4000 \mathrm{~cm}^{-1}$.

\subsection{Ultraviolet light irradiation}

The accelerated light-fastness test of specimens was conducted in a QUV light-fastness tester (Q-Panel Company) equipped with UVA-351 fluorescent lamps. It operates over a $315-\mathrm{nm}$ to $400-\mathrm{nm}$ range with a peak emission at $351 \mathrm{~nm}$. The temperature of the black panel was $60 \pm 2{ }^{\circ} \mathrm{C}$.

\subsection{ESR analyses}

The electron spin resonance (ESR) spectra were obtained by Bruker EMX-10 spectrometer. The frequency of microwave is $9 \mathrm{GHz}$. The temperature of sample was set at $-196{ }^{\circ} \mathrm{C}$. The power of the mercury lamp was $200 \mathrm{~W}$. To evaluate the tested specimens in the same $\mathrm{C}_{9}$ units, formations of phenoxyl radicals of both MWL specimen ( $5 \mathrm{mg}$ ) and butyrylated MWL specimen $(6.8 \mathrm{mg})$ under UV irradiation were measured, respectively, at different irradiation durations.

\subsection{UV-VIS absorption spectral analyses}

The UV-VIS spectra were measured using a UVVIS spectrophotometer (Jasco V-550) using $1 \mathrm{~cm}$ cells. The scanning range was from 200 to $800 \mathrm{~nm}$. The weight of MWL and butyrylated MWL were 5 and $6.8 \mathrm{mg}$, respectively. The water-soluble extracts of MWL and butyrylated MWL after irradiation were measured by UV-VIS absorption spectroscopy.

\section{Result and discussions}

\subsection{Chemical characteristics of butyrylated $M W L$}

Fig. $1 \mathrm{~b}$ shows the ${ }^{1} \mathrm{H}$ NMR spectrum of butyrylated MWL $\left(W_{\mathrm{G}} 36 \%\right)$. The appearance of absorption peak at $0.77 \mathrm{ppm}$ of treated specimen is due to the methyl group $\left(\mathrm{CH}_{3}\right)$. The $1.43 \mathrm{ppm}$ and $2.17 \mathrm{ppm}$ bands of the treated specimen are due to the methylene group $\left(\mathrm{CH}_{2}\right)$ and the methylene group adjacent to the carbonyl group $\left(\mathrm{CH}_{2} \mathrm{C}=\mathrm{O}\right)$, respectively. Data from the NMR analyses clearly revealed that the reaction occurred in the MWL and the butyryl groups were formed after treatment.

The FT-IR spectrum of MWL treated with butyric anhydride is shown in Fig. 2b. Obviously, the $\mathrm{O}-\mathrm{H}$ absorption band $\left(3430 \mathrm{~cm}^{-1}\right)$ of butyrylated MWL 
a

言

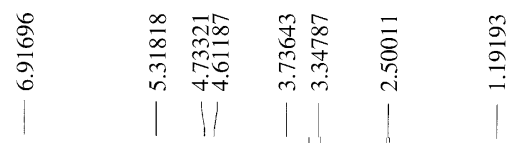
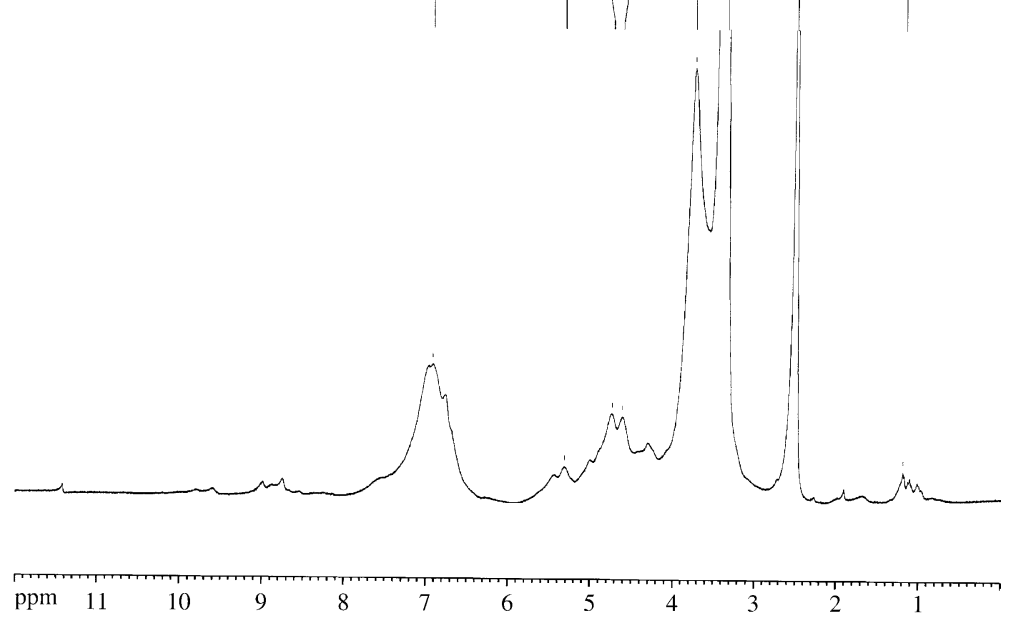

b

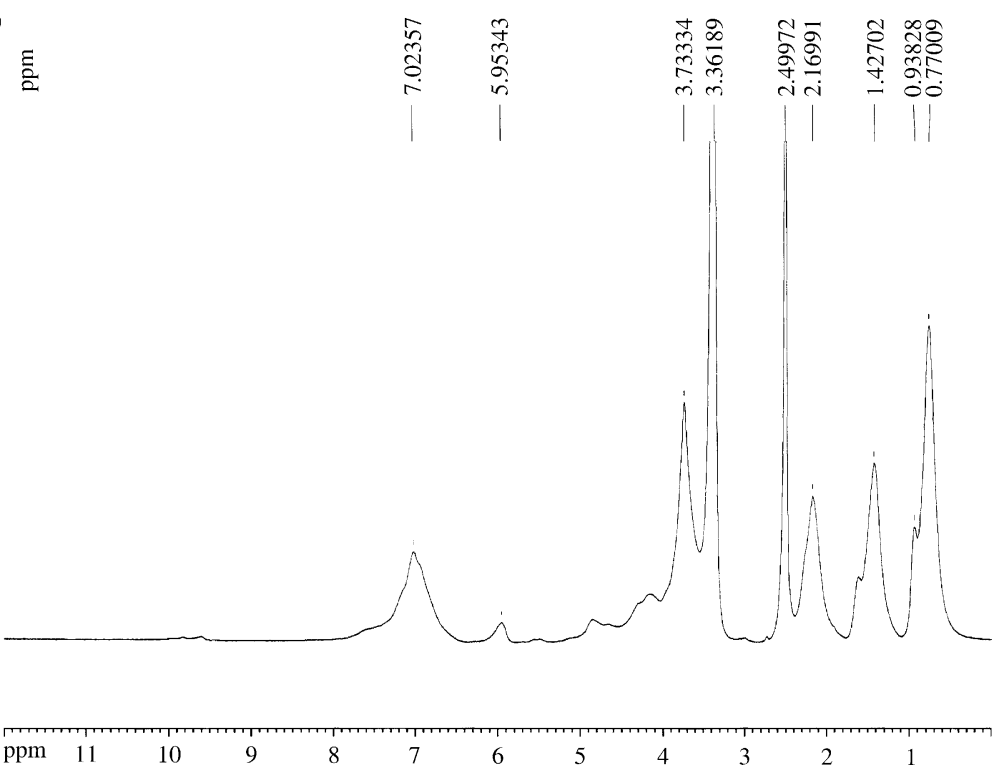

Fig. 1. ${ }^{1} \mathrm{H}$ NMR spectra of China fir MWL after butyrylation. (a) MWL; (b) butyrylated MWL.

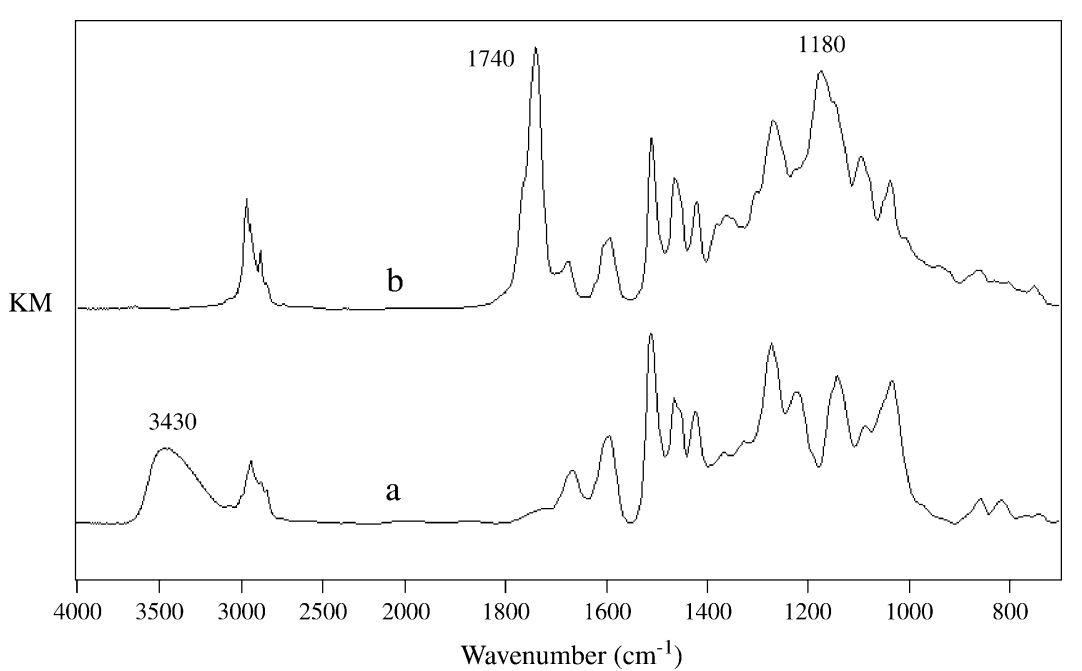

Fig. 2. FT-IR spectra of China fir MWL after butyrylation. (a) MWL; (b) butyrylated MWL. 
disappeared, which was consistent with the previous results [18]. A significant reduction in the hydroxyl group content of MWL revealed that the butyryl groups substituted nearly the hydrogen atoms of the entire hydroxyl groups of MWL after modification. The carbonyl absorption peak appearing at $1740 \mathrm{~cm}^{-1}$ and the enhanced $\mathrm{C}-\mathrm{O}$ absorption band $\left(1180 \mathrm{~cm}^{-1}\right)$ confirmed the formation of ester bond after butyrylation.

\section{a}

$\left[* 10^{\wedge} 3\right]$

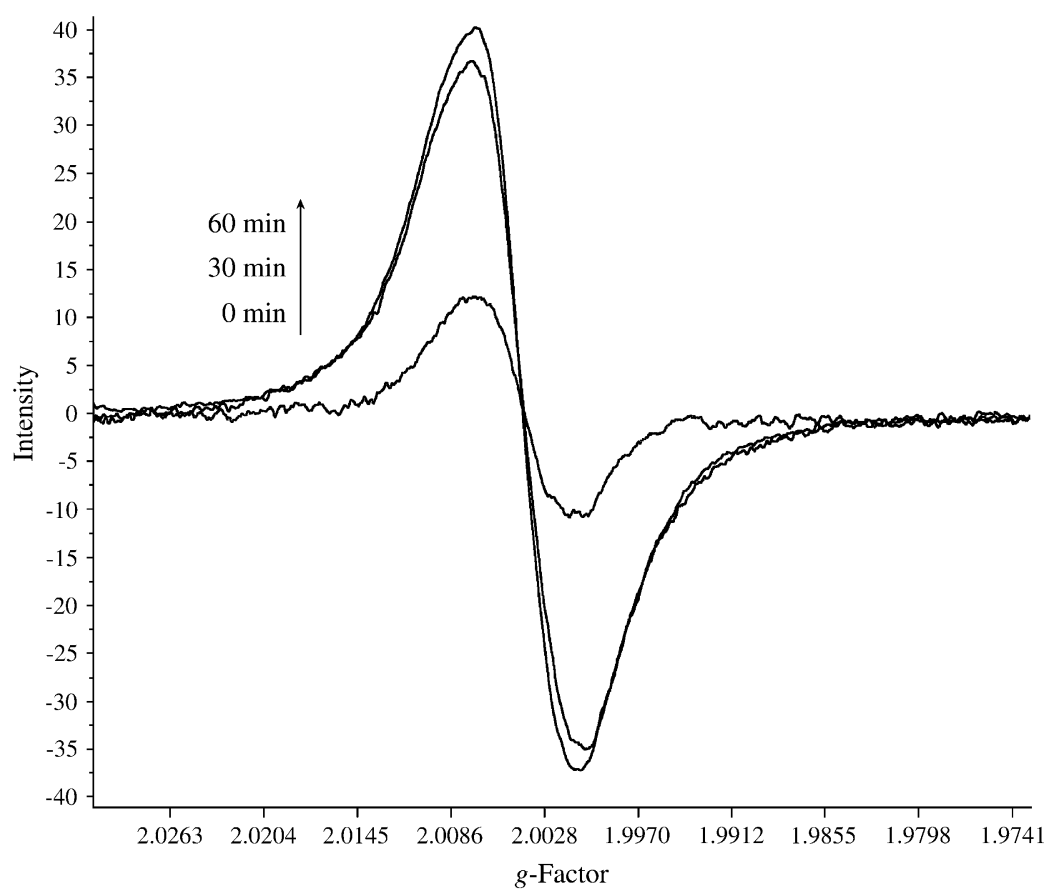

b

$\left[* 10^{\wedge} 3\right]$

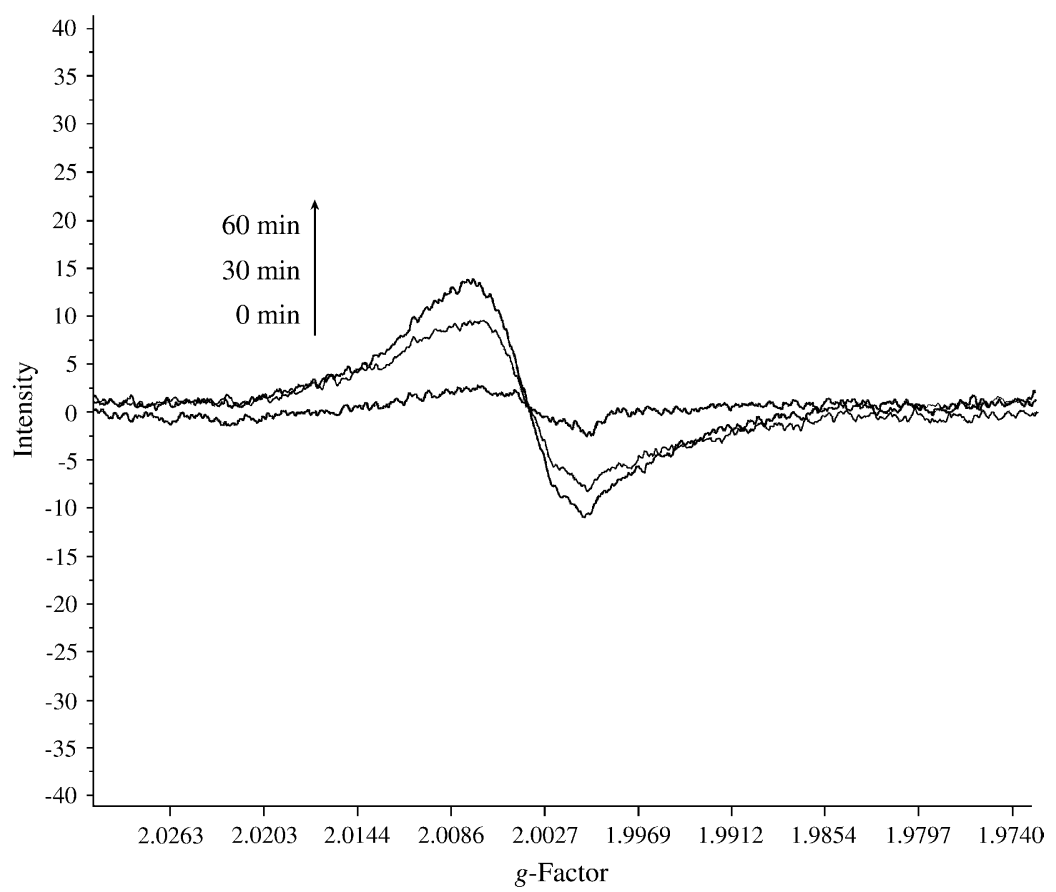

Fig. 3. ESR spectra of butyrylated MWL during UV light irradiation. (a) MWL; (b) butyrylated MWL. 


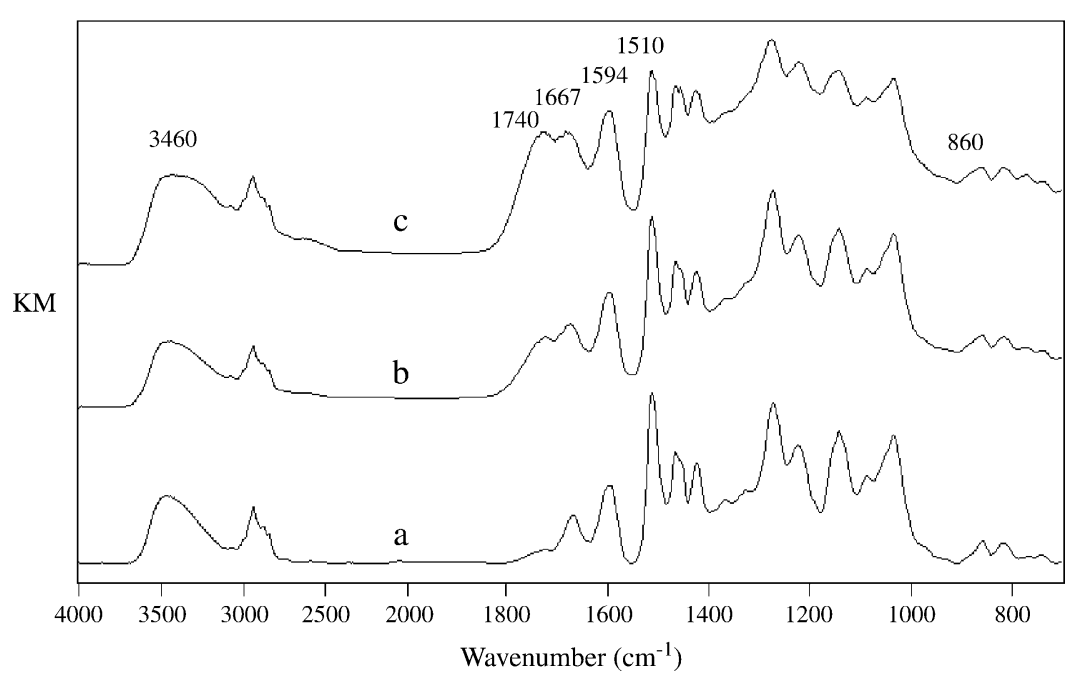

Fig. 4. FT-IR spectra of MWL after irradiation. (a) Unirradiated; (b) 4-day irradiation; (c) 12-day irradiation.

\subsection{Photo-stabilising effect of $M W L$ after butyrylation treatment}

Fig. 3a shows ESR spectra of untreated China fir MWL before and after exposing to UV irradiation. The ESR signal of phenoxyl radicals ( $g$ value $\approx 2.003$, line width $=16 \mathrm{G}$ [23]) from the photolysis of wood continuously increased over time $(0-60 \mathrm{~min})$. These phenoxyl radicals would cause further photo-degradation of MWL. The ESR spectra of sample modified with butyric anhydride are shown in Fig. 3b. Before the irradiation, modified specimen generated much less phenoxyl radicals than the untreated sample. Similarly, the intensity of phenoxyl radical of treated specimen slightly increased during the irradiation, whereas that of phenoxyl radicals was approximately 3 fold less than that of untreated sample. The ESR data reveal clearly that the butyrylation inhibits the generation of phenoxyl radicals in wood during irradiation.

The chemical structures of MWL changed significantly after irradiation, as shown in Fig. 4. An increase in the intensity of absorption band at $1740 \mathrm{~cm}^{-1}(\mathrm{C}=\mathrm{O})$ suggested that the content of carbonyl groups of MWL increased after exposure to UV light (Fig. 4b and c). The relative peak height ratio of non-conjugated carboxylic acid and ester to total carbohydrates is $0.61\left(I_{1740} / I_{860}\right.$, in Table 1) for MWL specimen before irradiation. The $I_{1740} / I_{860}$ ratio increased to 5.61 after 12 days of irradiation. The relative ratio of conjugated carbonyl group $\left(1667 \mathrm{~cm}^{-1}\right)$ for unexposed MWL was 1.93 , which increased to 5.23 after 12 days of irradiation. This obvious increase in the intensity of absorption band at $1667 \mathrm{~cm}^{-1}$ (conjugated carbonyl group) indicated the generation of derivatives containing the conjugated carbonyl group after irradiation. The broad $\mathrm{O}-\mathrm{H}$ absorption band occurring at $3460 \mathrm{~cm}^{-1}$ in relation to the increase in the carbonyl group revealed the formation of the carboxylic acid. As for the relative peak height ratio of the lignin aromatic ring characteristic band $\left(I_{1510} / I_{860}\right.$, in Table 1$)$, it decreased upon extending the irradiation time, from 7.89 to 5.64; and its retention ratio was $71.5 \%$. The decrease in the intensity of absorption band at $1510 \mathrm{~cm}^{-1}$ (aromatic skeletal vibration) indicated that the aromatic ring of lignin was deteriorated after 12-day UV irradiation.

Fig. 5 shows the changes of butyrylated MWL after irradiation. Broadening of the absorption peak at $1740 \mathrm{~cm}^{-1}(\mathrm{C}=\mathrm{O})$ indicated a slight increase in the content of carbonyl groups of butyrylated wood. The relative peak height ratio of $I_{1740} / I_{860}$, as shown in

Table 1

Changes in the relative intensities of infrared absorption bands of MWL and butyrylated MWL after irradiation

\begin{tabular}{|c|c|c|c|c|c|c|}
\hline Specimens & Irradiation time (day) & $I_{1510} / I_{860}$ & $I_{1594} / I_{860}$ & $I_{1667} / I_{860}$ & $I_{1740} / I_{860}$ & $I_{3450} / I_{860}$ \\
\hline \multirow[t]{3}{*}{ Control } & 0 & 7.89 & 3.40 & 1.93 & 0.61 & 2.85 \\
\hline & 4 & 6.68 & 4.43 & 3.06 & 2.58 & 3.30 \\
\hline & 12 & 5.64 & 5.83 & 5.23 & 5.61 & 4.78 \\
\hline \multirow[t]{3}{*}{ Butyrylation } & 0 & 6.95 & 3.46 & 2.11 & 11.67 & 0.17 \\
\hline & 4 & 6.53 & 4.23 & 2.45 & 11.92 & 0.79 \\
\hline & 12 & 6.41 & 4.40 & 2.96 & 12.15 & 1.33 \\
\hline
\end{tabular}




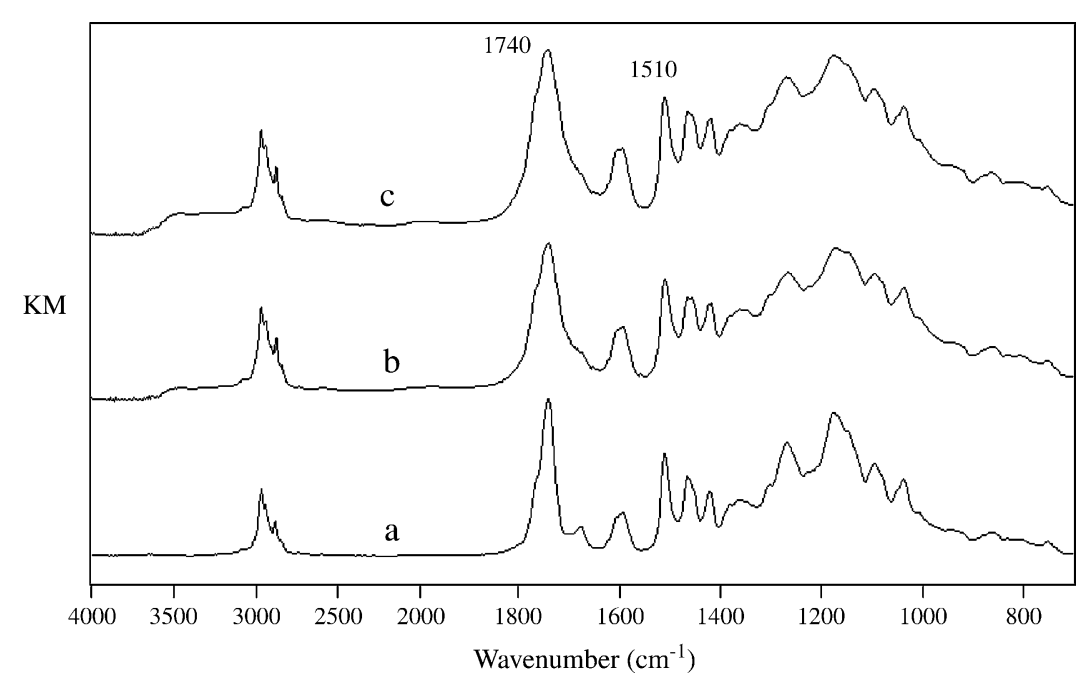

Fig. 5. FT-IR spectra of butyrylated MWL after irradiation. (a) Unirradiated; (b) 4-day irradiation; (c) 12-day irradiation.

Table 1, increased slightly from 11.67 to 12.15 as the irradiation time was prolonged. The ratio $I_{1510} / I_{860}$ decreased from 6.95 to 6.41 after 12-day irradiation. The decrease in the intensity at $1510 \mathrm{~cm}^{-1}$ (lignin aromatic ring) of butyrylated MWL was less than that of MWL. These results demonstrated that the butyrylated MWL was more resistant to the UV light.

Fig. 6 shows the UV absorption spectra of watersoluble extracts of both MWL and butyrylated MWL after 12 days of irradiation. The UV absorption bands at $203.5,232$, and $282 \mathrm{~nm}$ observed in the spectrum of the water-soluble extracts of MWL were due to small amounts of low molecular weight (MW) and watersoluble lignin (Fig. 6b). After irradiation, the UV absorption of water-soluble extracts of MWL increased dramatically (Fig. 6d). The striking UV absorption bands appearing at 241 and $260 \mathrm{~nm}$ were attributable to the unsaturated bond and carbonyl groups. The UV

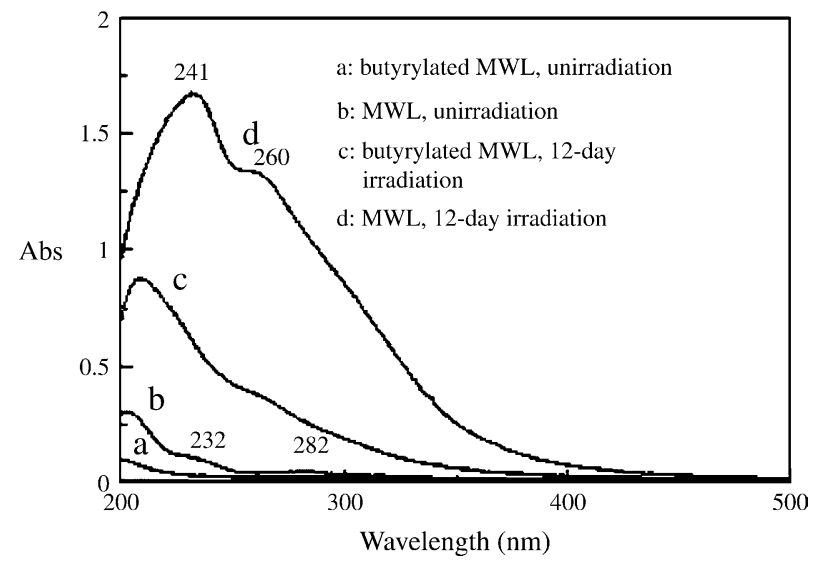

Fig. 6. UV absorption spectra of water-soluble extracts of MWL and butyrylated MWL after irradiation. absorption above $300 \mathrm{~nm}$ of the water-soluble extracts from irradiated MWL also increased, indicating the formation of conjugated chromophores, such as quinonoid compounds $[7,17]$.

The UV absorption bands of the water-soluble extracts of butyrylated MWL (Fig. 6a) were less than those of MWL. The water-soluble derivatives of butyrylated MWL increased after irradiation (Fig. 6c). The absorption intensity in the UV and visible light regions of butyrylated MWL was less than that of MWL after irradiation. It showed that butyrylation could reduce the amount of chromophores induced by UV light.

Results obtained from the aforementioned spectral analyses revealed that hydroxyl groups of MWL were replaced by butyryl groups after the butyric anhydride treatment. Since the formation of phenoxyl radicals was inhibited effectively. After UV irradiation, the butyrylated MWL was more resistive to UV light. Accordingly, butyrylation reduced the generation of colored chromophoric derivatives such as quinonoid compounds and consequently inhibited the photo-degradation of MWL, which is one of the possible reasons endowing the butyrylated wood with remarkable light-fastness $[18,19]$.

\section{Conclusion}

The generation of phenoxyl radicals of butyrylated MWL was less compared with the untreated MWL during UV irradiation. Meanwhile, the carbonyl and conjugated carbonyl groups for forming chromophores, such as quinones, and water-soluble derivatives generated in the irradiated MWL were significantly reduced by butyrylation. These results demonstrated that the lignin bonded with butyryl group was more stable and resistant against UV light. 


\section{References}

[1] Dence CW, Lin SY. Introduction. In: Lin SY, Dence CW, editors. Methods in lignin chemistry. New York: Springer-Verlag; 1992. p. 3 [chapter 1].

[2] Chang ST, Hon DNS, Feist WC. Photodegradation and photoprotection of wood surfaces. Wood Fiber 1982;14(2):104-17.

[3] Feist WC, Rowell RM, Ellis WD. Moisture sorption and accelerated weathering of acetylated and methylacrylated aspen. Wood Fiber Sci 1991;23:128-36.

[4] Chang ST, Chang HT. Evaluation of surface color characteristics and lightfastness of wood by spectral reflectance curve. Quart J Chin For 1995;29:31-44.

[5] George B, Suttie E, Merlin A, Deglise X. Photodegradation and photostabilisation of wood - the state of the art. Polym Degrad Stab 2005;88(2):268-74.

[6] Sjoholm R, Holmbom B, Akerback N. Studies of the photodegradation of spruce lignin by NMR spectroscopy. J Wood Chem Technol 1992;12(1):35-52.

[7] Heitner C. Light-induced yellowing of wood-containing papers. In: Heitner C, Scaiano JC, editors. Photochemistry of lignocellulosic materials. New York: American Chemical Society; 1993. p. 2 [chapter 1].

[8] Jaeger C, Nourmamode A, Castellan A. Photodegradation of lignin: a photochemical study of phenolic coniferyl alcohol lignin model molecules. Holzforschung 1993;47:375-90.

[9] Agarwal UP. Assignment of the photoyellowing-related $1675 \mathrm{~cm}^{-1}$ raman/IR band to $p$-quinones and its implications to the mechanism of color reversion in mechanical pulps. J Wood Chem Technol 1998;18(4):381-402.

[10] Li C, Ragauskas AJ. Brightness reversion of mechanical pulps part XIII: photoinduced degradation of lignin on cellulose matrix. J Wood Chem Technol 1999;19(1):43-60.

[11] Beaton CR, Argyropoulos DS. Photostabilizing milled wood lignin with benzotriazoles and hindered nitroxide. Photochem Photobiol 2001;73(6):605-10.
[12] Pan X, Harvey LC, Raguaskas AJ. Brightness reversion of mechanical pulps. Part VI: Cooperative photostabilization approaches for high-yield pulps. J Pulp Paper Sci 1996;22:135-40.

[13] Trichet V, Grelier S, Castellan A, Choudhury H, Davidson RS Attempt to photostabilize paper made from high-yield pulp by application of UV screens in conjunction with thiols. J Photochem Photobiol A Chem 1996:95:181-8.

[14] Rowell RM. Chemical modification of wood. In: Hon DNS, Shiraishi N, editors. Wood and cellulosic chemistry. New York: Marcel Dekker Inc.; 1990. p. 703 [chapter 15].

[15] Francis RC, Dence CW, Alexander TC, Agnemo R, Omori S. Photostabilization of thermomechanical pulps by alkylation and borohydride reduction. Tappi 1991;74:127-33.

[16] Hu TQ, James BR. Towards inhibition of yellowing of mechanical pulps. Part IV: Photostability of hydrogenated lignin model compounds. J Pulp Paper Sci 2000;26:173-5.

[17] Paulsson M, Lucia LA, Ragauskas AJ, Li C. Photoyellowing of untreated and acetylated aspen chemithermomechanical pulp under argon, ambient, and oxygen atmosphere. J Wood Chem Technol 2001;21:343-60.

[18] Chang ST, Chang HT. Inhibition of the photodiscoloration of wood by butyrylation. Holzforschung 2001;55(3):255-9.

[19] Chang HT, Chang ST. Improvements in dimensional stability and lightfastness of wood by butyrylation using microwave heating. J Wood Sci 2003;49(5):455-60.

[20] Peng PP, Argyropoulos DS. On the interaction of UV screens with the lignocellulosic matrix. Photochem Photobiol 2000;71(2): 149-56.

[21] Bjorkman A. Studies on finely divided wood. Part 1. Extraction of lignin with neutral solvent. Sven Papperstidn 1956;59: 477-85.

[22] Wegener G, Fengel D. Rapid ultrasonic isolation of milled wood lignins fractionation and degradation experiments. Tappi 1979; 62(3):97-100

[23] Hon DNS, Ifju G, Feist WC. Characteristics of free radical in wood. Wood Fiber 1980;12(2):121-30. 